\title{
Transfusion strategy for acute upper gastrointestinal bleeding
}

Reviewed by: James Handel, MD*; Eddy Lang, MD*

\begin{abstract}
Clinical question
Does a hemoglobin transfusion threshold of $70 \mathrm{~g} / \mathrm{L}$ yield better patient outcomes than a threshold of $90 \mathrm{~g} / \mathrm{L}$ in patients with acute upper gastrointestinal bleeding?

Article chosen

Villanueva C, Colomo A, Bosch A, et al. Transfusion strategies for acute upper gastrointestinal bleeding. $N$ Engl J Med 2013;368(1):11-21.

Study objectives

The authors of this study measured mortality, from any cause, within the first 45 days, in patients with acute upper gastrointestinal bleeding, who were managed with a hemoglobin threshold for red cell transfusion of either $70 \mathrm{~g} / \mathrm{L}$ or $90 \mathrm{~g} / \mathrm{L}$. The secondary outcome measures included rate of further bleeding and rate of adverse events.
\end{abstract}

Keywords: bleeding, gastrointestinal, transfusion

\section{BACKGROUND}

Patients with acute upper gastrointestinal bleeding commonly present to emergency departments for diagnosis and management. ${ }^{1}$ These patients will potentially require red cell transfusion; however, the optimal strategy for transfusion has remained controversial., ${ }^{2,3}$ Previous studies have suggested that a lower hemoglobin threshold for red cell transfusion can be safe and effective, but those studies did not include patients with gastrointestinal bleeding. ${ }^{4,5}$ Current Canadian guidelines for management of nonvariceal upper gastrointestinal bleeding fail to address a hemoglobin threshold for red cell transfusion, ${ }^{6}$ whereas British guidelines for the same suggest red cell transfusion whenever hemoglobin concentration falls below $100 \mathrm{~g} / \mathrm{L}{ }^{7}$ There have been no studies that directly assess whether a restrictive threshold for red cell transfusion in patients with acute upper gastrointestinal bleeding is more effective than a liberal transfusion strategy.

\section{STUDY DESIGN}

This single center, randomized controlled trial, consecutively enrolled patients with acute upper gastrointestinal bleeding from June 2003 through December 2009. Patients were concealed, but unblinded, to a restrictive transfusion strategy or a liberal transfusion strategy, with additional stratification for the presence or absence of liver cirrhosis. Those assigned to the restrictive strategy had a hemoglobin threshold for transfusion of $70 \mathrm{~g} / \mathrm{L}$, whereas, for those assigned to the liberal strategy, it was $90 \mathrm{~g} / \mathrm{L}$; the target ranges for posttransfusion hemoglobin were $70-90 \mathrm{~g} / \mathrm{L}$ and $90-110 \mathrm{~g} / \mathrm{L}$, respectively. Additional transfusions were administered for symptoms or signs of anemia, massive bleeding, or when surgery was required. Patients with variceal bleeding had portal pressure estimated, using the hepatic venous pressure gradient, ${ }^{8}$ within the first 48 hours and again 2-3 days later, to assess the effect of the transfusion strategy on portal hypertension. The intention-to-treat principle was applied to statistical analysis.

\section{POPULATION INCLUDED AND STUDIED}

Inclusion criteria were patients over age 18 , presenting with hematemesis (or bloody nasogastric aspirate),

From the *Division of Emergency Medicine, University of Calgary, Calgary, AB.

Correspondence to: Dr. James Handel, Division of Emergency Medicine, University of Calgary, 1403 29th Street NW, Room C-231, Calgary, AB T2N 2T9; Email: j_handel@ymail.com 
melena, or both, confirmed by hospital staff. Patients were excluded if they had massive exsanguinating bleeding; an acute coronary syndrome; symptomatic peripheral vasculopathy; stroke, transient ischemic attack, and transfusion within the last 90 days; recent history of trauma or surgery; lower gastrointestinal bleeding; a previous decision by a physician that the patient should avoid specific medical therapy; a clinical Rockall score of 0 with a hemoglobin level greater than $120 \mathrm{~g} / \mathrm{L}$; or if the patient declined to undergo a blood transfusion.

\section{OUTCOMES MEASURED}

The primary outcome measure was the rate of mortality, from any cause, within 45 days. Secondary outcomes were the rate of further bleeding and the rate of adverse events.

\section{RESULTS}

There were 2,372 patients admitted to the hospital for gastrointestinal bleeding during the study period. Of these, 1,610 were screened for inclusion; 41 declined and 648 were excluded, leaving 921 patients for randomization. Baseline characteristics of the two groups, including the stratification for liver cirrhosis, were similar.

Mortality at 45 days was significantly lower in the restrictive strategy compared to the liberal strategy $(5 \%$ v. $9 \%, p=0.02)$. In the cohort of patients with liver cirrhosis, mortality was not significantly different. In the subgroup of patients with liver cirrhosis, ChildPugh class A or B, mortality was significantly lower in the restrictive strategy versus the liberal strategy. In patients with Child-Pugh class $\mathrm{C}$, bleeding varices, or a bleeding peptic ulcer, there was no significant difference in mortality (Table 1). Death was due to unsuccessfully controlled bleeding in 3 patients in the restrictive group and 14 patients in the liberal group (0.7\% v. $3.1 \%, p=0.01)$.

There was a $10 \%$ rate of further bleeding in the restrictive strategy compared to $16 \%$ in the liberal strategy $(p=0.01)$. The overall rate of adverse events was significantly lower in the restrictive strategy group compared to the liberal strategy ( $40 \%$ v. $48 \%, p=0.02$ ). The length of hospital stay was significantly shorter for the restrictive strategy patients compared to those in the liberal strategy (9.6 days v. 11.5 days, $p=0.01$ ).

\section{STUDY CONCLUSION}

The authors conclude that a restrictive transfusion strategy, compared to a liberal transfusion strategy, significantly improves outcomes (mortality, further bleeding, and adverse events) in patients presenting with an acute upper gastrointestinal bleed, and therefore, deferring red cell transfusion until hemoglobin falls below $70 \mathrm{~g} / \mathrm{L}$ is a safe and effective approach.

\section{COMMENTARY}

In patients presenting with an acute upper gastrointestinal bleed, this is the first study directly assessing the efficacy of a restrictive versus a liberal red cell transfusion strategy, and there was a significant difference in mortality at 45 days representing the number needed to treat of 25 . This result is consistent with similar studies conducted retrospectively ${ }^{9}$ or in a different setting ${ }^{10}$; however, there are a few discussion points to consider.

Death was due to uncontrolled bleeding in significantly more patients in the liberal versus the restrictive transfusion strategy; however, the authors do not mention whether these patients correspond to the variceal

Table 1. Subgroup analysis of death by 6 weeks

\begin{tabular}{|c|c|c|c|c|c|}
\hline \multirow[b]{2}{*}{ Subgroup } & Restrictive strategy & Liberal strategy & \multirow[b]{2}{*}{ Hazard ratio } & \multirow[b]{2}{*}{$95 \% \mathrm{Cl}$} & \multirow[b]{2}{*}{$P$ value } \\
\hline & \multicolumn{2}{|c|}{ No. of patients/total no. (\%) } & & & \\
\hline Overall & $23 / 444(5)$ & $41 / 445(9)$ & 0.55 & $0.33-0.92$ & 0.02 \\
\hline Patients with cirrhosis & 15/139 (11) & 25/138 (18) & 0.57 & $0.30-1.08$ & 0.08 \\
\hline Child-Pugh class A or B & $5 / 113(4)$ & 13/109 (12) & 0.30 & $0.11-0.85$ & 0.02 \\
\hline Child-Pugh class C & 10/26 (38) & $12 / 29(41)$ & 1.04 & $0.45-2.37$ & 0.91 \\
\hline Bleeding from varices & 10/93 (11) & $17 / 97(18)$ & 0.58 & $0.27-1.27$ & 0.18 \\
\hline Bleeding from peptic ulcer & $7 / 228$ (3) & $11 / 209(5)$ & 0.70 & $0.26-1.25$ & 0.26 \\
\hline
\end{tabular}


bleeding patients in the liberal transfusion strategy who were shown to have a significant increase in their hepatic venous pressure gradient, post-transfusion. This would be interesting to note, because previous literature has suggested that transfusing variceal bleeding patients contains a risk of causing further bleeding due to increased portal pressures. ${ }^{11-13}$

Furthermore, there was a significantly larger number of patients in the restrictive strategy compared to that in the liberal strategy $(8 \%$ v. $3 \%, p=0.001)$ who received transfusion when the hemoglobin was unknown because they were experiencing signs or symptoms of anemia, massive bleeding, or needed surgery. Although this was within the experimental design, it lends itself to speculation regarding the reason that this difference occurred. If patients in the restrictive group were somehow sicker at baseline, then the relative mortality benefit could be greater than the mortality identified in this study.

The major protocol violations in the study create an interesting possibility. In the restrictive strategy, $9 \%$ $(n=39)$ of patients received transfusion without signs or symptoms of anemia, massive bleeding, or surgery, and when hemoglobin was greater than $70 \mathrm{~g} / \mathrm{L}$; in the liberal transfusion strategy, $3 \%(n=15)$ of patients did not receive transfusion when their hemoglobin was below $90 \mathrm{~g} / \mathrm{L}(p<0.001)$. If the study hypothesis is valid, and mortality rate increases when red cells are transfused with hemoglobin above $70 \mathrm{~g} / \mathrm{L}$, then the mortality in the restrictive group would have been even lower if those 39 patients had not received transfusion in error, and, in the liberal group, mortality would have been higher if those 15 patients had received transfusion as intended.

Secondary outcomes also favoured a restrictive transfusion strategy. There were significantly less further bleeding and adverse events in the restrictive transfusion strategy. This is in keeping with some previous literature, ${ }^{5}$ but not others, which have suggested no difference in adverse events. ${ }^{14}$ Finally, as concerns of resource utilization are increasingly discussed, demonstrating a significantly lower use of blood products, as well as shorter hospital stays, in the restrictive transfusion strategy may allow for a more cautious use of these resources in the future.

\section{CONCLUSION}

In this first randomized study, to directly assess a restrictive versus a liberal transfusion strategy in patients with an acute upper gastrointestinal bleed, the results support a hemoglobin transfusion threshold of $70 \mathrm{~g} / \mathrm{L}$. Overall, it is a well-designed study, and some of the previous points suggest the possibility of a potentially greater mortality benefit with a restrictive transfusion threshold. Future research, with the power to detect a significant mortality difference in some of the subgroups, particularly patients with peptic ulcer disease, would be useful. In the meantime, a reasonable approach in the emergency department would be to initiate red cell transfusion when there are symptoms of anemia or massive bleeding, regardless of hemoglobin level, but to defer transfusion for hemodynamically stable patients with a hemoglobin concentration above $70 \mathrm{~g} / \mathrm{L}$.

Competing interests: None declared.

\section{REFERENCES}

1. Gralnek IM, Barkun AN, Bardou M. Management of acute bleeding from a peptic ulcer. $N$ Engl 7 Med 2008; 359(9):928-37.

2. Barkun AN, Bardou M, Kuipers EJ, et al. International consensus recommendations on the management of patients with nonvariceal upper gastrointestinal bleeding. Ann Intern Med 2010;152(2):101-13.

3. Barkun A, Bardou M, Marshall JK. Consensus recommendations for managing patients with nonvariceal upper gastrointestinal bleeding. Ann Intern Med 2003;139(10): 843-57.

4. Lacroix J, Hebert PC, Hutchison JS, et al. Transfusion strategies for patients in pediatric intensive care units. $N$ Engl 7 Med 2007;356(16):1609-19.

5. Hébert PC, Wells G, Blajchman MA, et al. A multicenter, randomized, controlled clinical trial of transfusion requirements in critical care. $N$ Engl 7 Med 1999;340(6):409-17.

6. Barkun A, Fallone CA, Chiba N, et al. A Canadian clinical practice algorithm for the management of patients with nonvariceal upper gastrointestinal bleeding. Can 7 Gastroenterol 2004;18(10):605-9.

7. British Society of Gastroenterology Endoscopy Committee. Nonvariceal upper gastrointestinal haemorrhage: guidelines. Gut 2002;51(Suppl 4):iv1-6.

8. Villanueva C, Ortiz J, Minana J, et al. Somatostatin treatment and risk stratification by continuous portal pressure monitoring during acute variceal bleeding. Gastroenterology 2001;121(1):110-7.

9. Hearnshaw SA, Logan A, Palmer KR, et al. Outcomes following early red blood cell transfusion in acute upper gastrointestinal bleeding. Aliment Pharmacol Ther 2010; 32(2):215-24.

10. Marik PE, Corwin HL. Efficacy of red cell transfusion in the critically ill: a systematic review of the literature. Crit Care Med 2008;36(9):2667-74. 
11. McCormick PA, Jenkins SA, McIntyre N, et al. Why portal hypertensive varices bleed and bleed: a hypothesis. Gut 1995;36(1):100-3.

12. Castaneda B, Morales J, Lionetti R, et al. Effects of blood volume restitution following a portal hypertensive-related bleeding in anesthetized cirrhotic rats. Hepatology 2001; 33(4):821-5.
13. Boyer JL, Chatterjee C, Iber FL, et al. Effect of plasma volume expansion on portal hypertension. $N$ Engl $\mathcal{7}$ Med 1966;275:750-5.

14. Jairath V, Hearnshaw S, Brunskill SJ, et al. Red cell transfusion for the management of upper gastrointestinal haemorrhage. Cochrane Database Syst Rev 2010;9: CD06613. 